\title{
PENGARUH GELLING AGENT TERHADAP PEMBENTUKAN OLEOGEL BERBASIS CANOLA OIL
}

\author{
Dhyna Analyes Trirahayu1, ${ }^{1,}$ dan Budi Santoso ${ }^{1}$ \\ ${ }^{1}$ Jurusan Teknik Kimia, Politeknik Negeri Bandung \\ Jln. Gegerkalong Hilir, Ds. Ciwaruga, Bandung 40012 \\ "E-mail: dhyna.analyes@ polban.ac.id
}

\begin{abstract}
ABSTRAK
Indonesia merupakan negara dengan kekayaan hayati tinggi. Salah satu hasil kehutanan yang melimpah di Indonesia adalah pulp. Selain sebagai kertas, pulp juga dapat diolah menjadi produk turunan lain yang memiliki nilai jual lebih tinggi, salah satunya selulosa. Kandungan selulosa dalam pulp cukup tinggi dapat mencapai lebih dari $90 \%$. Dari selulosa ini banyak produk turunan yang dapat dihasilkan dengan nilai ekonomi yang lebih tinggi dan sangat bermanfaat. Turunan selulosa dapat dimanfaatkan sebagai gelling agent salah satunya untuk membentuk oleogel. Oleogel adalah gel di mana fasa cairnya adalah minyak, berbeda dengan hidrogel, yang memiliki fasa cair air. Potensi aplikasi dari oleogel sangat beragam di industri makanan, farmasi, kosmetik, dan petrokimia. Salah satu produk turunan selulosa yang dapat dimanfaatkan sebagai gelling agent adalah hydroxypropyl methyl cellulose (HPMC). Penelitian ini bertujuan untuk melakukan observasi terhadap pembentukan oleogel berbasis minyak canola dengan menggunakan HPMC dan Xanthan Gum (XG) sebagai gelling agents. Pembentukan oleogel dilakukan menggunakan kombinasi HPMC dan XG dengan komposisi yang divariasikan menggunakan metode pengadukan. Oleogel terbaik diperoleh menggunakan kombinasi gelling agent $\mathrm{HPMC}: \mathrm{XG}=1: 1$ sebanyak 2 gr $(2 \% \mathrm{~b} / \mathrm{b})$.
\end{abstract}

Kata kunci: Minyak canola, HPMC, oleogel, selulosa

\begin{abstract}
Indonesia is a country with rich bioresoures. One of the abundant forestry products in Indonesia is pulp. Aside from being paper raw material, pulp can also be processed into other derivative products that have a higher selling value, one of which is cellulose. The cellulose content in the pulp is quite high, it can reach more than $90 \%$. From this cellulose many derivative products can be produced with higher economic value and aplication. Cellulose derivatives can be used as gelling agents, one of which is to form oleogel. Oleogel is a gel in which the liquid phase is oil, in contrast to the hydrogel, which has a liquid phase of water. Potential applications of oleogel are very diverse in the food, pharmaceutical, cosmetic and petrochemical industries. In the food industry, oleogel has the potential to minimize oil migration in multi-component foods, such as chocolate containing cream, and to provide structure for vegetable oils, thereby reducing the need for saturated and trans fatty acids. One of the cellulose derivative products that can be used as a gelling agent is hydroxypropyl methyl cellulose (HPMC). The research objective is to observe the canola oil based oleogel formation using HPMC and Xanthan Gum (XG) as gelling agents. The oleogel formation use combination of HPMC and XG with varied composition by mixing. The best oleogel is obtained using a combination of gelling agent HPMC: Xanthan Gum =1: 1 as much as $2 \mathrm{gr}(2 \% \mathrm{w} / \mathrm{w})$.
\end{abstract}

Keywords: Canola oil, HPMC, oleogel, cellulose 


\section{PENDAHULUAN}

Indonesia merupakan negara dengan kekayaan hayati tinggi. Salah satu hasil kehutanan yang melimpah di Indonesia adalah pulp. Selain sebagai kertas pulp juga dapat diolah menjadi produk turunan lain yang memiliki nilai jual lebih tinggi, salah satunya selulosa. Kandungan selulosa dalam pulp cukup tinggi dapat mencapai lebih dari 90\% (Wustenberg, 2015). Dari selulosa ini banyak produk turunan yang dapat dihasilkan dengan nilai ekonomi yang lebih tinggi dan sangat bermanfaat (Prabhu, 2005). Turunan selulosa dapat dimanfaatkan sebagai gelling agent salah satunya untuk membentuk oleogel. Oleogel adalah gel di mana fasa cairnya adalah minyak, berbeda dengan hidrogel, yang memiliki fasa cair air. Potensi aplikasi dari oleogel sangat beragam di industri makanan, farmasi, kosmetik, dan petrokimia. Dalam industri makanan, oleogel berpotensi untuk meminimalkan migrasi minyak dalam makanan multikomponen, seperti cokelat berisi krim, dan untuk menyediakan struktur bagi minyak nabati, sehingga mengurangi kebutuhan asam lemak jenuh dan trans (Hughes, 2009). Salah satu produk turunan selulosa yang dapat dimanfaatkan sebagai gelling agent adalah hydroxypropyl methyl cellulose (HPMC) (Phillips, 2000).

Penelitian terkait pembentukan oleogel dari berbagai minyak nabati dan gelling agent telah banyak dilakukan. Manipulasi terhadap kekuatan mekanik olegel yang dibuat menggunakan ethyl cellulose (Gravelle, 2016). Pembentukan dan karakteristik oleogel berbasis minyak kedelai dan berbagai bahan pengental (Meng, 2018). Pengaruh temperatur terhadap pembentuk oleogel menggunakan ethylcellulose (Davidovich-Pinhas, 2015). Tujuan dari penelitian ini adalah untuk melakukan observasi terhadap pembentukan oleogel berbasis minyak canola dengan menggunakan HPMC dan Xanthan Gum (XG) sebagai gelling agents.

\section{METODE}

Percobaan yang dilakukan adalah membuat oleogel berbasis canola oil dan turunan selulosa. Percobaan dilakukan dalam dua tahap, pembentukan oleogel dan penentuan oil loss.

\section{Bahan dan Peralatan}

Canola oil yang digunakan merupakan minyak goreng komersial. HPMC dan XG yang digunakan diperoleh di pasaran. Oleogel dibentuk dengan menvariasikan jumlah dan jenis gelling agent yang digunakan. Air suling digunakan untuk pelarutan sampel bubuk. Konsentrasi semua sampel disajikan sebagai persentase massa $(\% \mathrm{~b} / \mathrm{b})$. Peralatan yang digunakan, gelas kimia $250 \mathrm{ml}$, batang pengaduk, hot plate, stirrer bar, dan spatula.

\section{Pembentukan Oleogel}

Metode pembentukan oleogel mengacu pada Patel (2013) dengan modifikasi. Pembentukan oleogel dilakukan dengan mencampurkan minyak canola dengan gelling agent sesuai variasi yang telah ditetapkan. Bubuk HPMC dan XG disiapkan dengan menimbang jumlah akurat bubuk tersebut dan melarutkannya ke dalam air suling. Setelah semua bubuk larut tambahkan minyak secara berlahan sambal dilakukan pengadukan. Proses pengadukan berlangsung pada temperatur $120^{\circ} \mathrm{C}$ tekanan atmosperik selama 45 menit. Pertama bahan pengental dilarutkan di dalam air. Setelah itu minyak canola dituang secara perlahan sambil dilakukan pengadukan. Produk yang dihasilkan kemudian diamati. 


\section{Penentuan Oil Loss}

Kapasitas oleogel untuk mengikat minyak diukur menggunakan metode centrifugasi. (Blake \& Marangoni, 2015). Secara singkat, sekitar $30 \mathrm{~g}$ sampel oleogel (m1) ditimbang dalam botol plastik berukuran $50 \mathrm{~mL}$ dan disentrifugasi pada $5000 \mathrm{rpm}$ selama 30 menit. Minyak cair yang dilepaskan dikeluarkan dari vial sepenuhnya. Botol oleogel yang tersisa di dalam vial centrifuge setelah penghilangan minyak ditimbang (m2). Nilai kehilangan minyak dihitung dengan menggunakan Persamaan (1), di mana m1 adalah massa sampel awal dan $\mathrm{m} 2$ adalah massa sampel setelah pengeringan kelebihan minyak.

Oil loss $=\left(\mathrm{m}_{1}-\mathrm{m}_{2}\right) / \mathrm{m}_{1} \times 100 \%$

\section{Kestabilan Penyimpanan}

Kestabilan oleogel dalam masa simpan diamati dengan melihat perubahan produk selama 30 hari pada temperatur ruang. Karakteristik diamati berupa visual (warna dan struktur) dan bau.

\section{HASIL DAN PEMBAHASAN Pembentukan Oleogel}

Baik HPMC dan XG disetujui sebagai aditif bahan makanan, yang masing-masing digunakan terutama sebagai bahan penstabil dan pengental. Sementara XG diperoleh secara alami sebagai produk fermentasi dari strain bakteri tertentu, HPMC disintesis secara kimia dengan mensubstitusi beberapa gugus hidroksil pada selulosa alami dengan gugus hidropobik metoksi, HPMC menampilkan aktivitas permukaan dan karenanya digunakan untuk stabilisasi dispersi koloid seperti emulsi dan busa. XG, di sisi lain, memiliki permukaan non aktif tetapi masih dapat membantu dalam stabilisasi koloid (bila digunakan bersama dengan stabilizer aktif permukaan) dengan memperpanjang stabilitas kinetik melalui peningkatan viskositas fase massal. Untuk pekerjaan kami, $60 \%$ berat minyak dalam emulsi air adalah disiapkan hanya menggunakan $\mathrm{MC}$, hanya $\mathrm{XG}$ dan kombinasi $\mathrm{MC}$ - XG sebagai stabilisator. Variasi gelling agent dan hasil pembentukan oleogel ditampilkan pada Tabel 1 dan Gambar 1. Terlihat bahwa oleogel terbentuk ketika gelling agent yang digunakan merupakan kombinasi dari HPMC dan XG. Oleogel terbaik dihasilkan pada variasi HPMC : $\mathrm{XG}=1$ : 1 dengan jumlah 2 gr $(2 \% \mathrm{~b} / \mathrm{b})$. Dimana banyaknya minyak diikat lebih baik dibandingkan variasi lainnya.

Tabel 1. Pembentukan Olegeol pada Berbagai Variasi Gelling Agent

\begin{tabular}{clcc}
\hline No. & \multicolumn{1}{c}{ Gelling agent } & Jumlah $(\mathrm{gr})$ & Hasil \\
\hline 1 & HPMC (tanpa air) & 1 & Tidak larut \\
2 & HPMC & 1 & Tidak terbentuk gel \\
3 & XG & 1 & Tidak terbentuk gel \\
4 & HEC & 1 & Tidak terbentuk gel \\
5 & HPMC $:$ XG $(3: 1)$ & 1 & Terbentuk gel \\
6 & HPMC $:$ XG $(3: 1)$ & 2 & Terbentuk gel \\
7 & HPMC $:$ XG $(1: 1)$ & 1 & Terbentuk gel \\
8 & HPMC $:$ XG $(1: 1)$ & 2 & Terbentuk gel \\
\hline
\end{tabular}




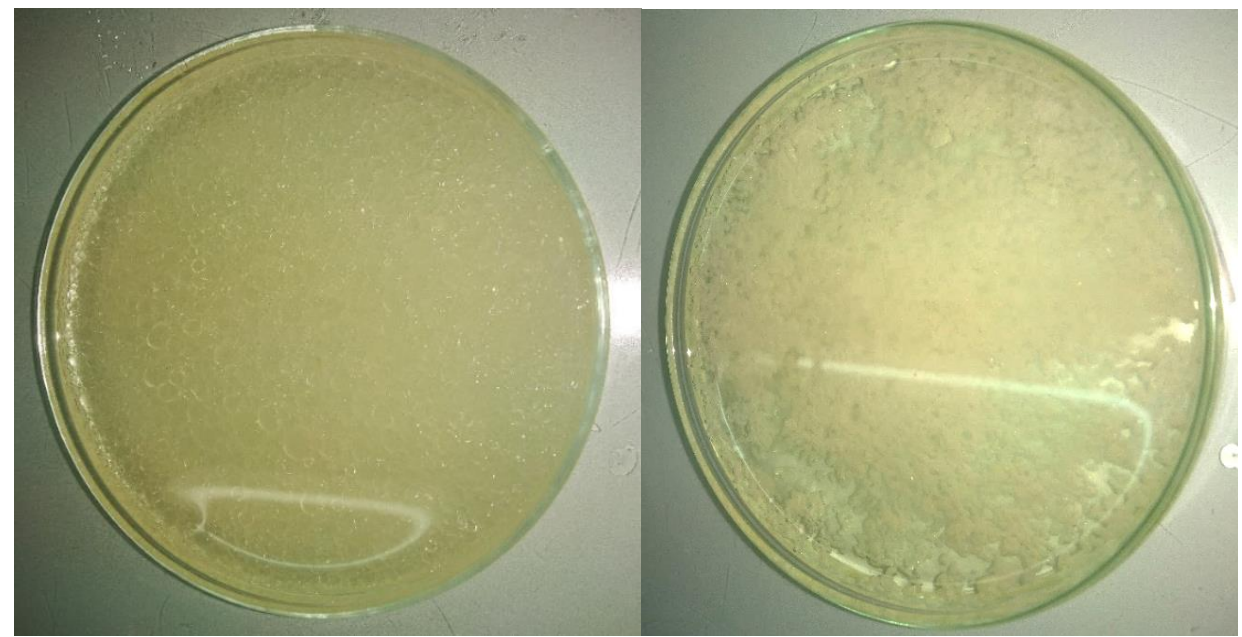

(a)

(b)

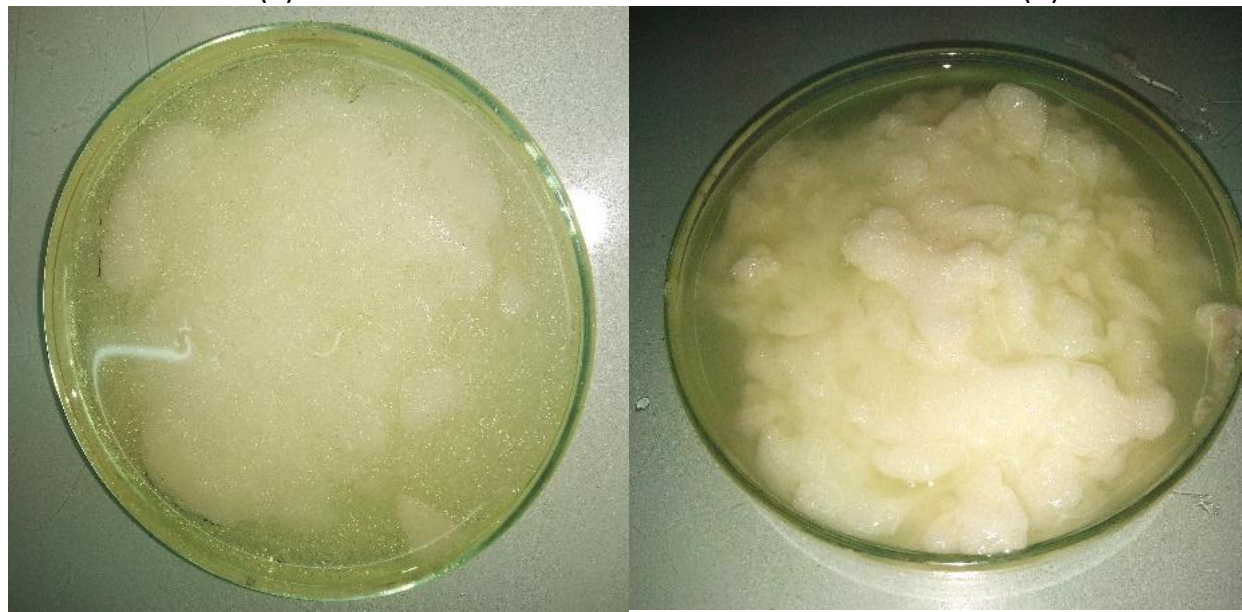

(c)

(d)

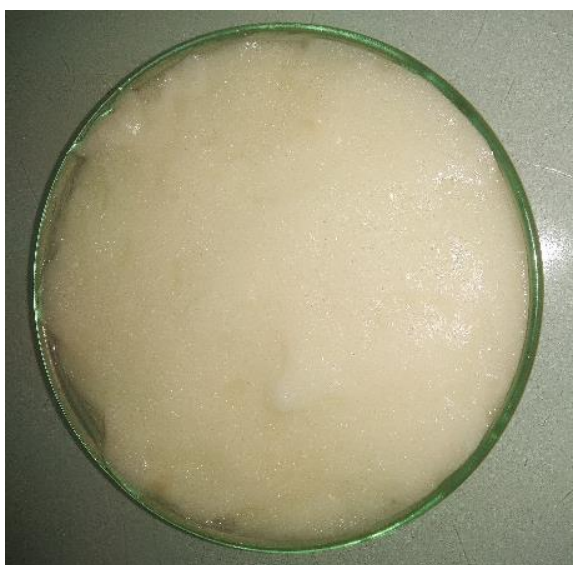

(e)

Gambar 1. (a) HPMC, (b) XG, (c) HPMC : XG = 3 : 1 (1gr), (d) HPMC : XG = 1 : 1 (1gr), (e) HPMC : XG = $1: 1$ (2gr)

Tabel 2. Penentuan Oil Loss

\begin{tabular}{cccc}
\hline No. & Gelling agent & Jumlah $($ gr $)$ & Oil Loss $(\%)$ \\
\hline 1 & HPMC $:$ XG $(3: 1)$ & 2 & $21 \%$ \\
2 & HPMC $:$ XG $(1: 1)$ & 2 & - \\
\hline
\end{tabular}


Menurut Daniel dan Rajasekaran (2003) pembentuk oleogel pada suhu ruang dapat dilakukan dengan asam lemak jenuh memiliki panjang rantai karbon 10 hingga 31. Semakin banyak jumlah asam lemak maka akan meningkatkan kemampuan pembentuk gel secara linear dengan peningkatan panjang rantai. Titik leleh oleogel meningkat dari 30 hingga $70^{\circ} \mathrm{C}$ dengan peningkatan panjang rantai asam lemak. Studi terkait gugus karboksil, menunjukkan bahwa posisi gugus hidroksil dan panjang rantai acyl berperan penting dalam pembentukan oleogel.

Gandolfo dkk (2004) juga mengamati potensi penyusunan asam lemak secara lebih rinci menggunakan serangkaian asam .lemak mulai dari rantai karbon 16 hingga 22 (asam palmitat, stearat, arakid dan asam behenic). Ditemukan bahwa FA dapat menyusun struktur minyak bunga matahari dan beberapa minyak nabati pada tingkat serendah $2 \%$ (b / b) pada $5^{\circ} \mathrm{C}$. Kekerasan oleogel meningkat secara linier dengan meningkatnya konsentrasi asam lemak, karena peningkatan jumlah padatan. Pada suhu konstan kelarutannya juga konstan

\section{Penentuan Oil Loss}

Kehilangan minyak dari oleogel yang diperoleh dengan menggunakan gelling agent yang berbeda telah ditunjukkan pada Tabel 2. Kehilangan minyak pada oleogel menunjukkan kapasitas relatif oleogel untuk mengikat minyak. Sebelum disentrifugasi, sampel oleogel mengandung lebih dari 97\% berat minyak cair. Setelah disentrifugasi, oleogel pada variasi 6 (HPMC : XG (3 : 1) kehilangan lebih banyak minyak dibandingkan dengan variasi 8 (HPMC : XG (1 : 1) (Gambar 2), yang menunjukkan kapasitas pengikatan minyak yang lemah. Kapasitas pengikatan oleogel minyak dapat dikaitkan dengan kekuatan mekanis emulsi dan oleogel dengan mempertimbangkan pengamatan nilai kehilangan minyak. Ditemukan bahwa emulsi dengan kekuatan mekanik yang lebih kuat cenderung menghasilkan oleogel dengan kekuatan gel yang lebih kuat dan kapasitas pengikatan minyak yang lebih baik (Patel, 2014).

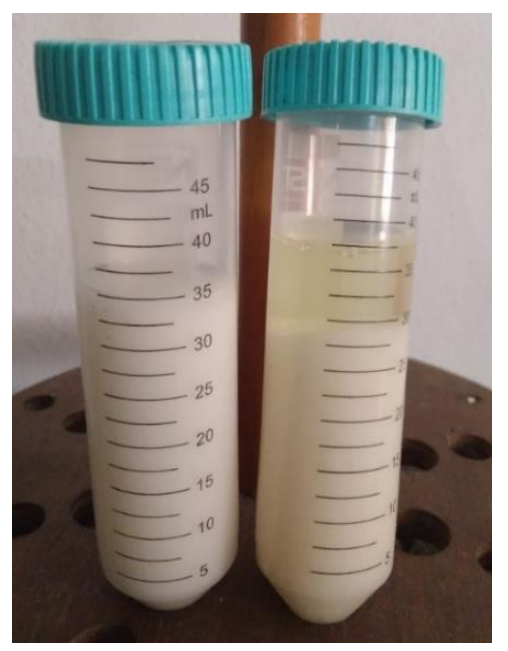

Gambar 2. Hasil Sentrifugasi Oleogel

\section{Kestabilan Penyimpanan}

Produk oleogel yang dihasilkan secara struktur tidak mengalami perubahan selama masa penyimpanan sekitar 30 hari pada suhu ruang (Gambar 3). Selama masa penyimpanan tidak terjadi perubahan struktur dan warna oleogel. Namun, dari sisi bau muncul bau yang kurang sedap yang diakibatkan karena produk oleogel teroksidasi.

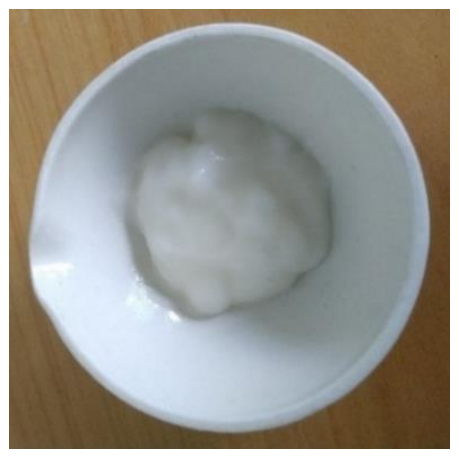

Gambar 3. Produk Oleogel 


\section{SIMPULAN}

Emulsi untuk persiapan oleogel diperoleh dengan menggunakan HPMC sebagai pengemulsi utama dalam kombinasi dengan XG sebagai bahan pengental. Semua emulsi yang dihasilkan tidak cukup stabil untuk melalui proses pengeringan untuk menghilangkan air. Kekuatan mekanik emulsi yang lebih kuat menunjukkan jaringan padatan lunak yang lebih ketat, kekuatan gel yang lebih kuat dan kapasitas oleogel yang lebih baik. Oleogel yang disiapkan oleh HPMC dan zat pengental lainnya menunjukkan perilaku yang tergantung waktu dan pemulihan struktur dan juga stabil dalam kisaran suhu yang luas. Selain itu, metode potensial untuk pembentukan oleogel telah berhasil dilakukan. Secara keseluruhan, penelitian ini menyediakan cara untuk membentuk oleogel yang dapat digunakan untuk aplikasi pada bahan makanan.

\section{UCAPAN TERIMA KASIH}

Penelitian ini didukung oleh dana dari DIPA Politeknik Negeri Bandung Tahun 2019 kontrak Nomor 560.44/PL1.R7/LT/2019.

\section{DAFTAR RUJUKAN}

Daniel, J.; \& Rajasekaran, R., 2003. Organogelation of plant oils and hydrocarbons by longchain saturated FA, fatty alcohols, wax esters, and dicarboxylic acids. $J \quad A m$ Oil Chem Soc, (80): 417-421.

Davidovich-Pinhas, M.; Gravelle, A. J.; Barbut, S.; Marangoni A. G., 2015. Temperature effects on the gelation of ethylcellulose oleogels. Food Hydrocolloids, (46): 76-83.

Gandolfo, F.G.; Bot, A.; \& Flöter, E., 2004. Structuring of edible oils by long-chain FA, fatty alcohols, and their mixtures. J Am Oil Chem Soc, (81): 1-6.
Gravelle, A. J.; Davidovich-Pinhas, M.; Zetzl, A.K.; Barbut,S.; \& Marangoni A.G., 2016. Influence of solvent quality on the mechanical strength of ethylcellulose oleogels. Carbohydrate Polymers, (135): 169179.

Hughes, N.E.; Marangoni, A.G.; Wright, A.J.; Rogers, M.A.; \& Rush, J.W.E., 2009. Potential food applications of edible oil organogels. Trends Food Sci Technol, (20): 470-80.

Meng, Z.; Keyu, Q.; Ying, G.; Yong, W.; \& Yuanfa, L., 2018. Effects of thickening agents on the formation and properties of edible oleogels based on hydroxypropyl methyl cellulose. Food Chemistry, (246): 137-149.

Patel, A. R.;Schatteman, D.; Lesaffer, A.; \& Dewettinck, K., 2013. A foamtemplated approach for fabricating organogels using a water-soluble polymer. Rsc Advances, III (45): 22900-22903.

Patel, A. R.; Cludts, N.; Bin Sintang, M. D.; Lesaffer, A.; \& Dewettinck, K., 2014. Edible oleogels based on water soluble food polymers: preparation, characterization and potential application. Food \& Function, V (11): 2833-2841.

Phillips, G. O.; \& Williams,P. A., 2009. Handbook of Hydrocolloids (Second Edition). New Delhi; Woodhead Publishing Series in Food Science, Technology and Nutrition.

Prabhu, D. M.; \& Wen-Jun L., 2015. The Most Abundant Natural Resource: Cellulose and Its Derivatives and Their Applications, New York; Nova Science Publishers, Inc.

Wüstenberg, T.; 2015. Cellulose and Cellulose Derivatives in the Food Industry: Fundamentals and Applications. Weinhem; WileyVCH. 